\title{
A Blended Collaborative Teaching Mode in Language Learning Based on Recommendation Algorithm
}

\author{
https://doi.org/10.3991/ijet.v16i23.27253 \\ Ting Wang \\ Zibo Vocational Institute, Zibo, China \\ ting5436@126. com
}

\begin{abstract}
With the continuous expansion of economic globalization, English, as the official language in the world, has a high popularity. It can be related to a better development in the future. Meanwhile, with the continuous progress of technology in modern society, multimedia online teaching has become the main means in colleges and universities, which especially brings great changes to foreign language teaching. However, foreign language teaching is facing many difficulties such as large number of contents, less lessons and low participation of students in class. Therefore, the reform of college foreign language teaching is imperative. Based on blended collaborative teaching mode, the paper has designed a "Three Classes" composed of "Communication Class", "Famous Teacher Class" and "Elite Online Class". Teaching process has been designed according to the cognitive process of "Previewing before class, consolidating in class and expanding after class". In addition, recommendation algorithm has been used to collect data on four dimensions, namely, involvement in foreign language learning, content completion of foreign language learning, interaction in foreign language learning and effectiveness of foreign language learning. A performance evaluation system for foreign language learning supported by big data has been established. The results of teaching practice have proved that the blended collaborative teaching mode implemented in the study can be integrated into the whole teaching process through intelligent data analysis, information sharing and technology application, improving teaching quality, enhancing the interaction between teachers and students, which is worthy of promotion and application.
\end{abstract}

Key Words-blended teaching, collaborative learning, college foreign language, recommendation algorithm

\section{Introduction}

With the rapid development of modern science and technology, knowledge can be transferred to others through informational means by using appropriate new media technologies. New media, with its special advantages, can be used in foreign language teaching in colleges to improve the teaching quality. Some teachers do not have enough recognition of how online teaching and traditional teaching can be collaborated, resulting in personalized online foreign language teaching not fully demonstrated, data of the 
interaction with students in the platform not deeply and thoroughly analyzed, and accurate teaching not fully embodied [1]. Meanwhile, there is not a system for the teaching modes of teachers, interaction with students in the teaching process is lacking, and the information of data is not enough to demonstrate the superiority of Blended teaching in foreign language teaching [2]. Therefore, it is an urgent problem to be solved that how foreign language teachers can make use of abundant online teaching resources to improve the teaching environment of foreign language in colleges and enhance the interaction between teachers and students.

College foreign language is one of the compulsory courses for students, one of the most important courses for students to complete their undergraduate study, and an important course to improve teaching quality. The course is highly practical which requires active learning. However, the time in class is limited, thus, it is beneficial to the deeper understanding of knowledge by introducing modern informational and interactive teaching mode. On this basis, the paper has explored to build a "Three Classes" composed of "Communication Class", "Famous Teacher Class" and "Elite Online Class" based on blended teaching mode. Meanwhile, interactive teaching has been implemented. Based on the characteristics of blended collaborative teaching mode and the needs of students, recommendation algorithm has been used to extract item characteristics from user ID and other data to provide online learning resources that students are interested in or are suitable for them. It is expected that the study can provide reference for the online and offline collaborative teaching of foreign language courses.

\section{State of the art}

Blended teaching is a type of online + offline teaching that combines the advantages of online teaching and traditional teaching [3]. Through the organic integration of these two teaching modes, learners can learn from easy things to in-depth knowledge and this teaching mode has become a hot research field for current educational reform. Compared to traditional face-to-face teaching, blended teaching supports the diversification of teaching and learners can freely express their ideas on the platform, share learning resources or participate in discussions. Therefore, many scholars have begun to explore a scientific way to use blended teaching to improve teaching effect. Akcaoglu et al. [4] believed that teachers should pay special attention to the social interaction of online learners, they discuss how placing students in small and permanent discussion groups can augment social presence. Designers and educators of online learning can strategically modify group size to promote social presence in asynchronous online discussions. Lee et al. [5] believed that teachers could better use various interactive tools to integrate online and offline teaching in the environment of intelligent classroom. This has been exemplified by guiding students to self-study, timely give them feedback, stimulate students to proactively participate in teaching activities and realizing highly effective and in-depth interaction between teachers and students. Hébert et al. [6] put forward that based on mobile devices and wireless communication, students' learning interest, attitude and performance could be effectively improved by designing mobile learning environment based on formative assessment on the online study platform. Hwang et al. 
[7] also believed that blended teaching based on intelligent classroom could provide convenience for teachers' innovation in teaching. In this environment, teachers could grasp students' learning status in time and effectively intervene to promote their offline learning, such as encouraging students to report and peer review. Auster et al. [8] used this blended learning as a form of online screencasts form that can be watched after class and applied in sociology courses in colleges. In teaching practices, the screencasts were used to introduce concepts and theories to provide more time for discussion in class and more opportunity for students to review concepts and theories outside of class. Investigations have shown that students consider screencasts to be helpful in positively affect the performance. Therefore, blended teaching mode can provide strong environmental support for the improvement of students' interests, learning motivation and interaction between teachers and students. The exploration of fully using blended teaching to further improve teaching effect will be one of the most effective ways to carry out teaching reform.

With the rapid development of current Internet technology, the teaching mode of foreign language in colleges is also constantly changing. Many scholars have discussed the disadvantages of traditional teaching mode in foreign language teaching, and have put forward numerous reform plan of curriculums, which greatly promoted the transformation of the teaching mode of foreign language in colleges. Chilingaryan \& Ekaterina [9] examined the potential of flipped classroom applying in foreign language teaching, and proposed that this teaching mode of foreign language could increase students' sense of responsibility and self-reliance; However, students' individualities, the characteristics of career-oriented teaching, as well as the age characteristics and other characteristics of each learning group should be taken into consideration. Mugimu et al. [10] put forward that communicative language teaching (CLT) should be applied in oral communication. This study intended to establish the availability and suitability of authentic instructional materials used in the implementation of CLT approach for German language in Uganda. They recommended that teachers become more creative in improvising locally available instructional materials in order to promote the teaching of German in everyday life, and that teacher training institutions should lay more emphasis on preparing teacher trainees of German in CLT approach. Cao Chang et al., Chinese scholars, first pointed out the disadvantages of unreasonable design of current college foreign language teaching activities and low level of students' participation in class. Thus, they put forward a new interactive foreign language mode, which was, the interactive teaching mode based on BYOD environment. The results of the teaching found that this mode was helpful to stimulate students' interest in learning and could help them establish a learning system of foreign language courses. Zeng et al. [11] proposed a teaching mode based on SPOC + Yuketang. In addition, $\mathrm{Li}$ [12] proposed an evaluation-driven teaching mode, which was to help students to design and complete tasks through evaluation between teachers and students. In this student-centred mode, every student's knowledge defect was corrected to improve their performance. However, those studies mainly focused on the reform of English courses in colleges and universities, few of which have involved the promotion of interaction between teachers and students and their interests in blended teaching. On this basis, the study intends to select a blended collaborative teaching mode, which is an extension and complement 
to blended teaching. Based on the analysis of the environment on the overall engagement of college students in learning, factors influencing their learning engagement have been analysed from three aspects such as students, teachers and classmates and intelligence of the learning environment, and put forward a blended algorithm extracting user related goods with graph neural network and extracting students' knowledge preference with deep learning.

\section{The integration of blended cooperative teaching mode into college foreign language teaching}

\subsection{The application of blended teaching mode in teaching}

Blended teaching mode takes students as the main body that teachers and students interact with each other. This model has a dynamic mechanism to fully mobilize teachers and students, stimulate students' inner desire for knowledge. However, it is also a test to teachers and students' learning initiative, enthusiasm and creativity. The blended collaborative teaching mode proposed in this study is an extension and complement to blended teaching. This mode requires teachers to actively change the traditional teaching mode, give priority to the guidance of students in the classroom, so that students can be self-oriented and their independent thinking abilities are stimulated. In this way, students can find their own weak links in learning, and actively think and solve problems. Finally, students' learning process is evaluated. In addition, teachers should understand knowledges that are easy to be misunderstood by students according to big data online and design interactive problems on this basis. In term of these problems, students normally misunderstand them. If problem-centered discussion can be carried out, students' desire in learning can be stimulated and the creativity between teachers and students can also be stimulated with an attitude of democracy, openness and equality. The interactive teaching process of college foreign language courses designed have not only included raising and solving questions, but also included independent thinking and cooperative learning, and the communication of learning outcomes. Besides, the acquisition of Internet information, providing instant communication platform for teachers and students and the intelligence and flexibility of online teaching have also been put emphasis on. The pre-class learning includes the use of network resources, the arrangement of pre-class exercises and online interaction for problems in the exercises; These problems will be solved in class and students are encouraged to solve problems using Internet big data. Meanwhile, students can cooperate with each other and demonstrate their group outcomes. Moreover, students can evaluate on teachers' teaching quality.

In the teaching process of foreign language in colleges, interactions between teachers and students and students' performance were evaluated. Through the college foreign language teaching assistant platform of blended teaching-based online teaching, data collection has been conducted on learning engagement, content completion, interaction degree and effectiveness of students' foreign language courses, and a learning performance evaluation system supported by big data has been established. In this system, 
the learning process of students and teaching process of teachers could be timely evaluated to provide information to teachers, letting them to intervene in students' learning attitude and method in time. The specific process was shown in Fig. 1.

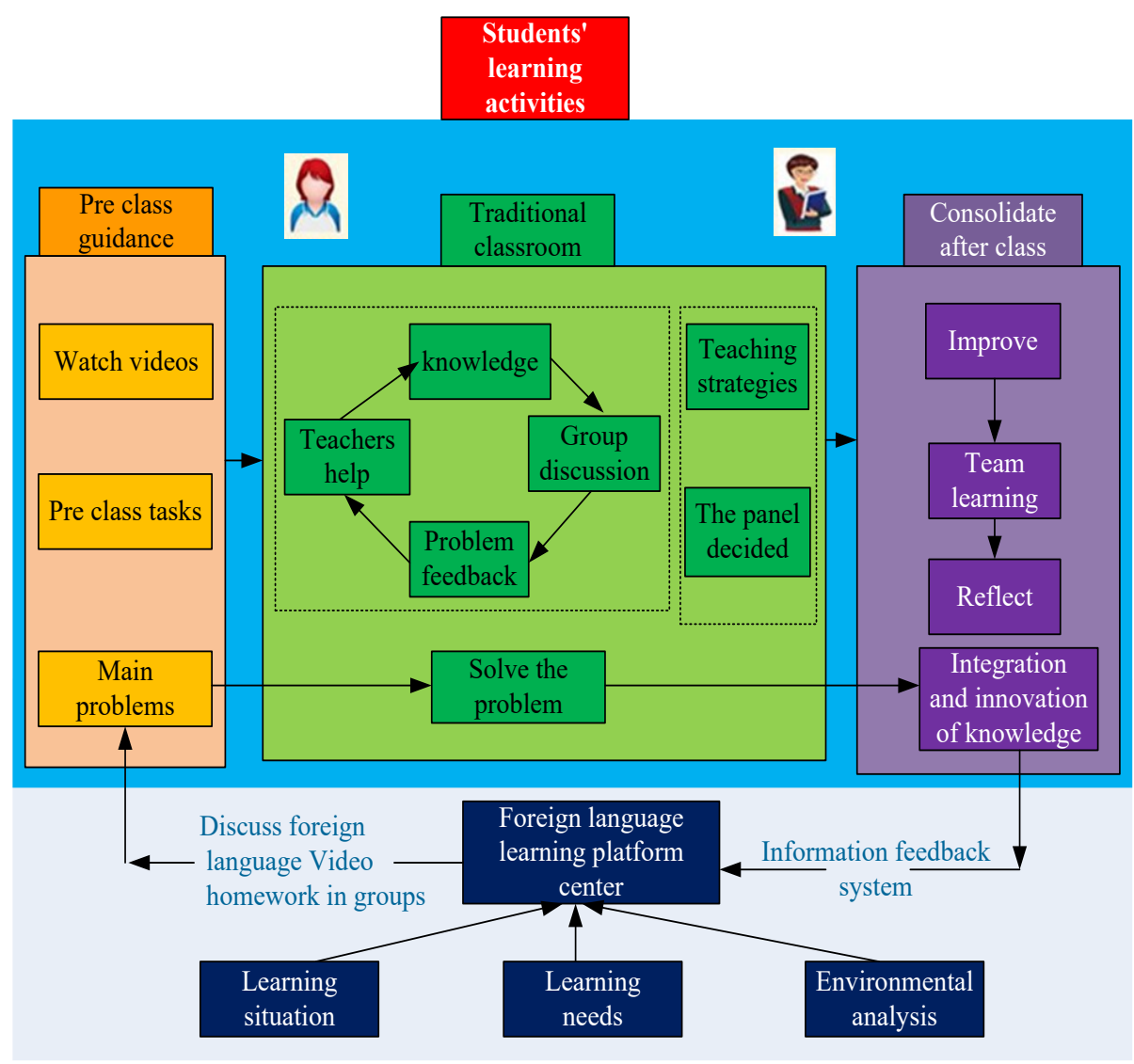

Fig. 1. Diagram of online collaborative knowledge construction

\subsection{Blended college foreign language teaching resource recommendation system based on graph neural network}

Graph Neural Network model is a neural network that operates directly on a graph structure. A typical application of GNN is node classification. Given a dataset D containing X samples, among which each sample $\left(u, i, r_{u i}\right)$ represented a comment $r_{u i}$ written by user $u$ on commodity i. As shown in Fig. 2, the core task of the study was to train a model to learn the association of user $u$ and commodity $i$ based on the interaction between all users and all commodities (excluding the interaction between user $u$ and commodity i). Meanwhile, based on the collection of user u's comments (excluding 
comment $r_{u i}$ of user $\mathrm{u}$ ), the collection of commodity i (excluding comment ${ }^{r_{u i}}$ of commodity i), the general preference representation of user $u$ and commodity I was learned, and the evaluation $P_{u i}$ of user u on commodity I was predicted according to the two characteristics.

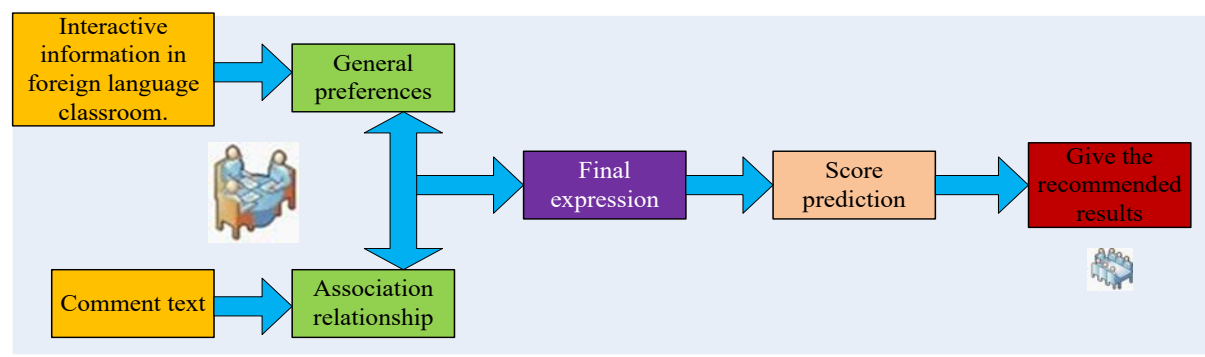

Fig. 2. Core method of the model

Assuming that there were $\mathrm{N}$ users, $\mathrm{M}$ commodities, then the ID embedded vector of the ith user could be represented as $e_{u i}^{(0)} \in R^{d}$, the ID embedded vector of the jth commodity could be represented as $e_{i j}^{(0)} \in R^{d}$, where d was the dimension of the embedded vector, which could be regarded as an adjustable hyperparameter. The ID embedded vector of all users formed a set, which was:

$$
e_{u}^{(0)}=\left[e_{u 1}^{(0)}, \cdots, e_{u i}^{(0)}, \cdots e_{u N}^{(0)}\right]
$$

In the same way, the ID embedded vector of all commodities formed a set $e_{i}^{(0)} \in R^{M x d}$, which was:

$$
e_{u}^{(0)}=\left[e_{i 1}^{(0)}, \cdots, e_{i j}^{(0)}, \cdots e_{i M}^{(0)}\right]
$$

The ID embedded vectors of commodities and users were both in the initial state, and the embedding was further refined by propagating in the forward propagation hierarchy, so that the ID embedded vector could better express the association inside it.

Assuming that the Binary chart constituted by all known associations was G. A method similar to LightGCN was used to extract the association between users and commodities. Taking commodity ij and user ui for example, the calculation rule of the ID of user ui embedded in graph convolutional network propagating once (i.e., onehop) was

$$
e_{u i}^{(1)}=\sum_{i_{j} \in N_{u}} \frac{1}{\sqrt{\left|N_{u}\right|} \sqrt{\left|N_{i}\right|}} e_{i_{j}}^{(0)}
$$

Where $e_{u i}^{(1)}$ was the representation of the first hop of the user ui in graph convolution, and $e_{u i}^{(0)}$ was the representation of the zero hop of the user ui in graph convolution, 
which was the ID embedding on the embedded hierarchy. $\frac{1}{\sqrt{\left|N_{u}\right|} \sqrt{\left|N_{i}\right|}}$ was the aggregation in the original design based on GCN, where $\mathrm{Nu}$ represented the collection of all neighbour nodes that contain the user ui, Ni represented the set of all neighbour nodes that contain commodity ij. To be simple, to obtain the embedding expression of the first hop of user ui in the graph, formula (3) has aggregated the initial ID embedding of all commodity nodes in all neighbour nodes of user ui, thus the first hop of embedding of ui in the graph was obtained.

Similarly, the calculation rule of the ID embedding of commodity ij in the network for one propagation was

$$
e_{i_{j}}^{(1)}=\sum_{u_{i} \in N_{i}} \frac{1}{\sqrt{\left|N_{i}\right|} \sqrt{\left|N_{u}\right|}} e_{u_{i}}^{(0)}
$$

The First-order propagation of nodes in graph convolutional network (Equation (3), (4)) has modelled the first-order correlation characteristics between users and items. By using the first-order calculation, hierarchical graph convolution could be stacked in graph convolution network to model the characteristics of high order relation between users and items. It could be concluded that the forward propagation rule (node aggregation rule) of the kth hop to the $(K+1)$ th hop in the convolution of the graph in the forward propagation hierarchy of user ui and commodity ij was defined as follows:

$$
\left\{\begin{array}{l}
e_{u i}^{(k+1)}=\sum_{i_{j} \in N_{u}} \frac{1}{\sqrt{\left|N_{u}\right|} \sqrt{\left|N_{i}\right|}} e_{i_{j}}^{(k)} \\
e_{i_{j}}^{(k+1)}=\sum_{u_{i} \in N_{i}} \frac{1}{\sqrt{\left|N_{i}\right|} \sqrt{\left|N_{u}\right|}} e_{u_{i}}^{(k)}
\end{array}\right.
$$

Where $e_{u i}^{(k+1)}$ and $e_{i_{j}}^{(k+1)}$ represented the embedding representation of the $(\mathrm{k}+1)$ th hop in graph convolution of user ui and commodity $\mathrm{ij}, e_{u i}^{(k)}$ and $e_{i_{j}}^{(k)}$ represented the embedding representation of the kth hop in graph convolution of user ui and commodity ij.

Finally, the expression of user ui and commodity ij was obtained as

$$
\left\{\begin{array}{l}
e_{u_{i}}=e_{u_{i}}^{(0)} \oplus e_{u_{i}}^{(1)} \oplus \cdots \oplus e_{u_{i}}^{(k)} \\
e_{i_{i}}=e_{i_{j}}^{(0)} \oplus e_{i_{j}}^{(1)} \oplus \cdots \oplus e_{i_{j}}^{(k)}
\end{array}\right.
$$

For better final expression of graph neural network, self-attention mechanism was used to model the importance of each hierarchy of embedding. For user ui, its graph neural network attention $a t t_{u_{i}} \in R^{1 \times k}$ was calculated as follows:

$$
a t t_{u_{i}}=\operatorname{softmax}\left(w_{1} \otimes \tanh \left(w_{2} \otimes e_{u_{i}}^{T}\right)\right)
$$

Where $w_{1} \in R^{1 \times t}, w_{2} \in R^{t \times d}, \mathrm{t}$ could be considered as adjustable hyperparameters. $a t t_{u_{i}}$ contained the weight $a t t_{u_{i}}^{(0)} \square a t t_{u_{i}}^{(k)}$ of the embedding expression from hierarchy 
0 to hierarchy K. The softmax () function was used to normalize the weights embedded in hierarchy $\mathrm{K}$.

By weighting and summing the embedded vectors of each hierarchy with the attention vector, the final embedding expression of ui's association $e_{u_{i}}^{\prime} \in R^{d}$ was obtained as

$$
e_{u_{i}}^{\prime}=\sum_{z=0}^{k} a t t_{u_{i}}^{(z)} e_{u_{i}}^{(z)}
$$

In the same way, the final embedding expression of ui's association $e_{i_{j}}^{\prime} \in R^{d}$ was obtained as

$$
e_{i_{i}}^{\prime}=\sum_{z=0}^{k} a t t_{i_{j}}^{(z)} e_{i_{j}}^{(z)}
$$

For the comment embedded vector $b_{u_{i}} \in R^{R N \times R L \times c}$ of user ui, assuming that there were m convolution kernels, each convolution kernel satisfied $K_{k i} \in R^{k s \times k s}$, where ks was the adjustable width of convolution kernel, for feature extraction of user ui's general preference, convolution operation was performed first:

$$
z_{u i}=\operatorname{Lerky} \operatorname{Re} L U\left(\operatorname{reshape}\left(b_{u_{i}}\right) * K_{k i}+\mu_{u_{i}}\right)
$$

Where the reshape operation converted the dimension of $b_{u_{i}}$ to a second-order tensor, let $b_{u_{i}} \in R^{(R N \times R L) \times c}$, * represented convolution, ui was the deviation. The vector obtained after a convolution satisfied $z \in R^{(R N \times R L)-k s+1}$. Since there were m convolution kernels, $m$ vectors $\mathrm{z}$ was produced by the convolution.

As one of the most widely used data sets in the recommendation system, Amazon data set has included the purchase records of 29 categories of goods from 1996 to 2018 , which includes commodity ID, user ID, comment text, commodity label and many other data information. The paper has used four 5-core (each item/user contains at least 5 interaction records) versions of data sets for the experimental verification of the model in the paper, including Automotive (Auto), Toys_and_Games, Tools_and_Home_Improvement (THI) Sports_and_Outdoors (SO). The model in this paper has used the product ID, user ID, and comment text data information in the data set.

For better training effect of the model, original data set was pre-processed before the experiment. Firstly, data needed was extracted from the total data set. Secondly, since there were empty values and too few words in the comment text data, it was necessary to carry out data cleaning on the comment text data. Empty comments could not reflect users' preferences for commodities, and even random filling could correctly express the preferences, thus, null comment data was removed. For data with too few comments, they were copied and filled; while for the data with too long comments, they were deleted (meaningless words and symbols with relatively low meaning, etc.), making the length of comments be unified as $\mathrm{RL}=50$. Through the statistical analysis of user ID and commodity ID, the data set of 10 -core version was made. The statistical information of the pre-processed dataset was shown in Table 1. 
Paper-A Blended Collaborative Teaching Mode in Language Learning Based on Recommendation ...

Table 1. Statistical table of data set

\begin{tabular}{|l|c|c|c|c|}
\hline Data set & Number of users & Number of commodities & Number of interactions & Sparse degree \\
\hline Auto & 15280 & 8157 & 226477 & 0.00182 \\
\hline TG & 15780 & 10345 & 267628 & 0.00164 \\
\hline THI & 26988 & 14240 & 417492 & 0.00109 \\
\hline SO & 33816 & 17142 & 533041 & 0.00092 \\
\hline
\end{tabular}

The study has used TopK recommendation method, where $\mathrm{K}=20$, and Recall rate and NDCG (Normalized Discounted Cumulative Gain) were used to evaluate the performance of the model. Recall was used to measure the proportion of the number of commodities with interactions among Top20 in the recommendation list to the number of all commodities with interactions among users in the test set. The higher the recall rate, the better the effect of the model. Assuming that the total user set of the test set was $\mathrm{U}$, for any user $u \in U$, the recommendation list of Top20 was Lu, the actual interaction list of user $\mathrm{u}$ in the test set was $L_{u}^{\text {test }}$, and, the calculation formula of model recall rate was

$$
\text { recall@20 }=\sum_{u \in U} \frac{1}{|U|} \frac{\left|L_{u} \cap L_{u}^{t e s t}\right|}{L_{u}^{t e s t}}
$$

NDCG has measured the correlation score of recommendation results at different locations in the recommendation list. The higher the relevance to users, the higher the ranking of recommended commodities, the better the recommendation effect, and the higher the score they had. NDCG has comprehensively evaluated the quality of recommendation lists of all users. Assuming that $L_{u}^{i}$ was the recommendation of the ith position in the Top20 list, $\mathrm{F}(\mathrm{x})$ was equal to 1 when $x>0$, and otherwise 0 . Assuming that the correlation score $r e l \in\{0,1\}$, then the calculation formula of NGCD was

$$
N D C G @ 20=\sum_{u \in U} \frac{1}{|U|} \frac{D C G_{u} @ 20}{I D C G_{u} @ 20}=\sum_{u \in U} \frac{1}{|U|} \frac{\sum_{i=1}^{20} \frac{f\left(L_{u} \cap L_{u}^{\text {test }}\right)}{\log _{2}(i+1)}}{\sum_{i=1}^{20} \frac{f\left(L_{u}^{\text {test }-i}\right)}{\log _{2}(i+1)}}
$$

\subsection{The application of blended collaborative teaching mode in college foreign language teaching}

With the development of the "Three Classes", the trend of mutual integration is becoming more and more obvious. The "Communication Class", "Famous Teacher Class" and "Elite Online Class" have gradually formed a large system that is both independent and interrelated, jointly promoting the balanced development of quality compulsory education. From their relationship, it could be seen that "Communication Class" solves students' problems while providing real teaching scenes for "Famous Teacher Class"; And "Famous Teacher Class" provided teachers for the improvement 
of teaching quality of "Communication Class" by promoting the professional development of teachers. They two classes cooperated with each other to promote the development of teaching and research, and provided basic support for the all-round and systematic application of high-quality resources of "Elite Online Class". On the contrary, the "Elite Online Class" constantly promoted the deepening development and innovative application of the "Communication Class" and "Famous Teacher Class". The three classes together constituted an ecosystem with mutual development, virtuous cycle, and mutual empowerment. Figure 3 has shown the "Communication Class" of the blended collaborative teaching mode.

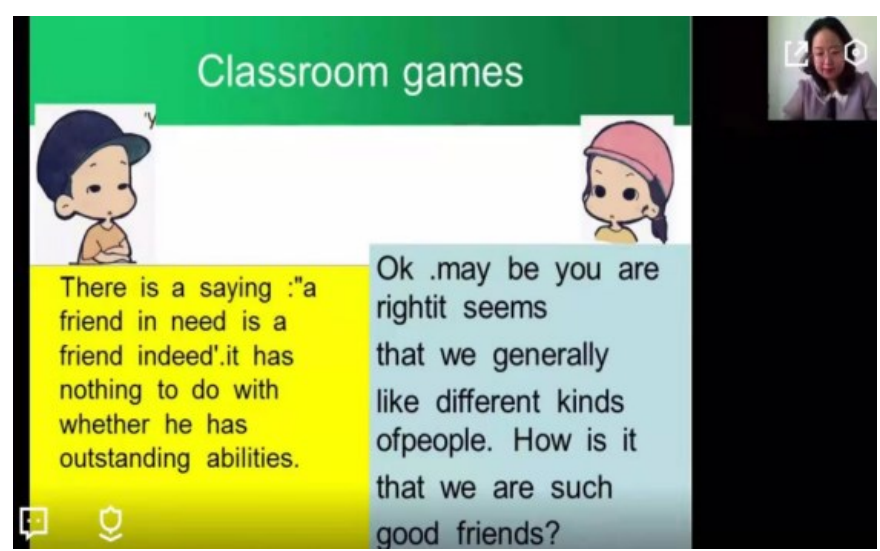

Fig. 3. The demonstration of "Communication Class" of blended collaborative teaching mode

This relationship was not the result of top-level design, but gradually evolved in practice, because there was inner logic for the formation of this relationship. The biggest challenge of the sustainable development of "Communication Class" was that the introduction of external digital teaching resources or excellent teachers would squeeze the living space of teachers in less developed colleges and universities, thus bring negative effect to the development of teachers in these colleges. Since teaching research and teaching cannot be separated, the biggest challenge of the sustainable development of "Elite Online Class" is that teaching researching which is separated from real teaching will become meaningless. As the means of collaborative development of teachers and the sharing of resources of elite teachers, the "Elite Online Class" used internet and other informational means to form a community of teachers, carrying out teaching researching on the practice of the "Communication Class", which not only solve their own problems of how to carry out teaching research based on real teaching, but also promote the sustainable development of teachers in less developed colleges, and help improve the teaching quality of "Communication Class". Meanwhile, by using the "Internet +", "Elite Online Class" is comprehensively, systematically and rapidly gathering and sharing of all quality education resources, including excellent teachers and digital resources, not only helping solve the problems of teaching and research, students' learning and development, but also helping solve the problems in the management and development related to teaching. Led by the new prospective and support from leaders, 
colleges should rely on digital resources, comprehensively reform in teaching, research and management, change the organizational structure and management mode of traditional teaching, change the s mode of development and improve the level of colleges, and create an "innovative digital college".

After years of exploration, the function of "Three Classes" in promoting the balanced promotion of compulsory education is becoming clearer and clearer. The "Three Classes" is the means, the core concept is to promote the reform in class, which is led by specific strategies in "Internet + localization", and finally the goal of balanced development of compulsory education will be achieved. On this basis, the study has established a concept frame of the "Three Classes" in promoting the balanced development of compulsory education, as shown in Fig. 4, in which the most important were the concept of "Internet + localization" and the strategy of "teacher-student interaction".

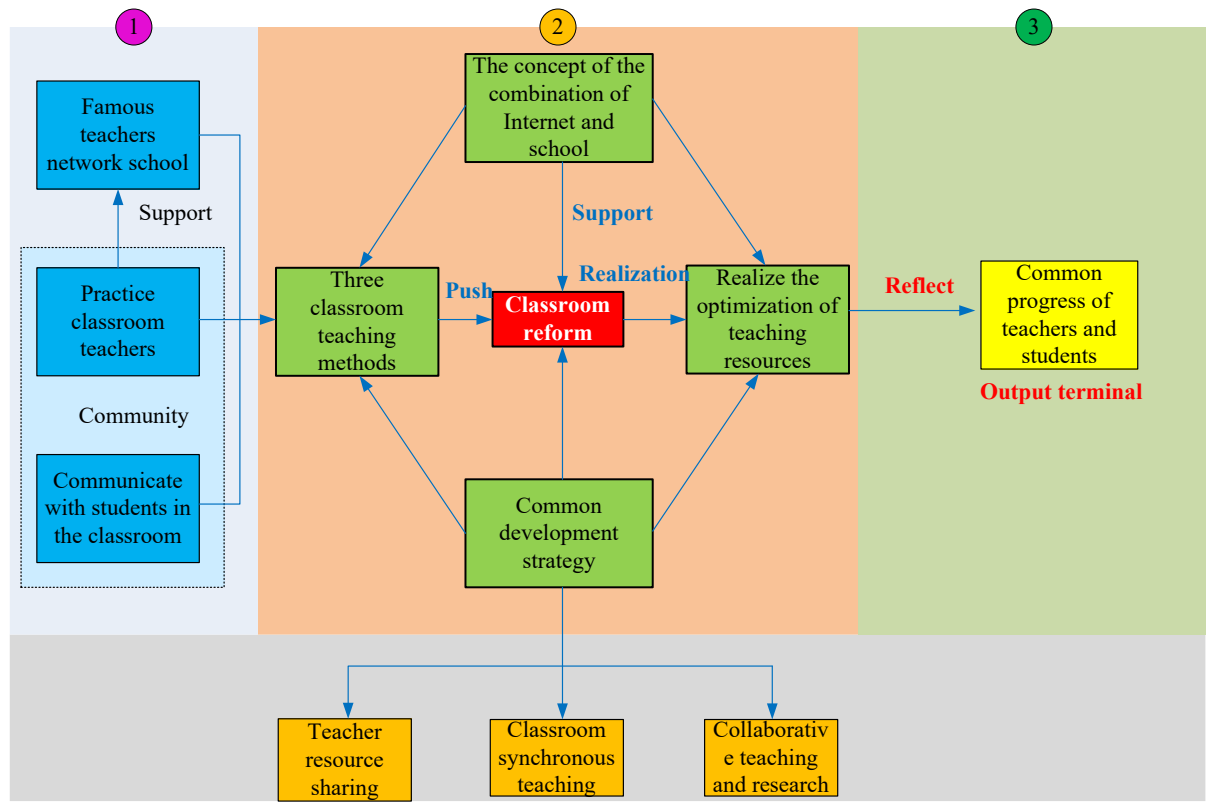

Fig. 4. Three classroom teaching design frameworks of blended collaborative teaching mode

\section{Teaching example and effect}

\subsection{Teaching example}

The implementation of the teaching mode and the design of the teaching steps were based on the process of "Previewing before class, consolidating in class and expanding after class".

Step 1: Preview before class. As shown in Fig. 5, in the pre-class learning of blended collaborative teaching mode, teachers firstly issued videos and learning contents through Wechat and required students to take notes while watching the videos and 
preview two English poems of stories; Students recorded difficult parts in the learning process; Meanwhile, the groups shall report their learning materials to the teacher in the form of PPT, and get feedback through Wechat or Email after the teacher had viewed and proposed modification advices. The purpose of pre-class design was to let students have some primary understanding about the background knowledge of the two authors and the content of the poems. By taking notes and recording difficult parts and raising questions, students' thinking was promoted and they could feel the context, thus their enthusiasm in class was enhanced.
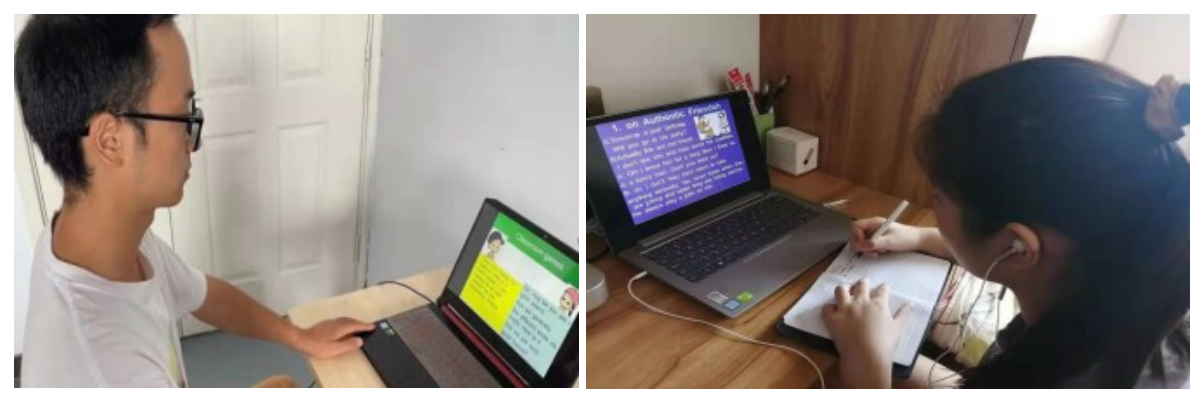

Fig. 5. Demonstration of pre-class learning scenario of blended collaborative teaching mode

Step 2: Consolidating in class. It could be seen from Fig. 6 that the process of consolidating in class of the blended collaborative teaching mode included group presentation, text reading, Q \& A discussion. The groups reported learning contents with PPT and proposed difficult parts as follows: (1) Some difficulties in understanding the course; (2) Learning the content of the course. Based on the questions raised by the groups, students compared the contents form whole and details and found the different parts. In addition, students understood the value of this English poem or short story from the perspective of writing and translating. Subsequently, students were organized to discuss on unsolved problems in the preview. For questions related to foreign literature and culture in class discussion, teachers participated as guests in class or answer questions through Wechat after class.

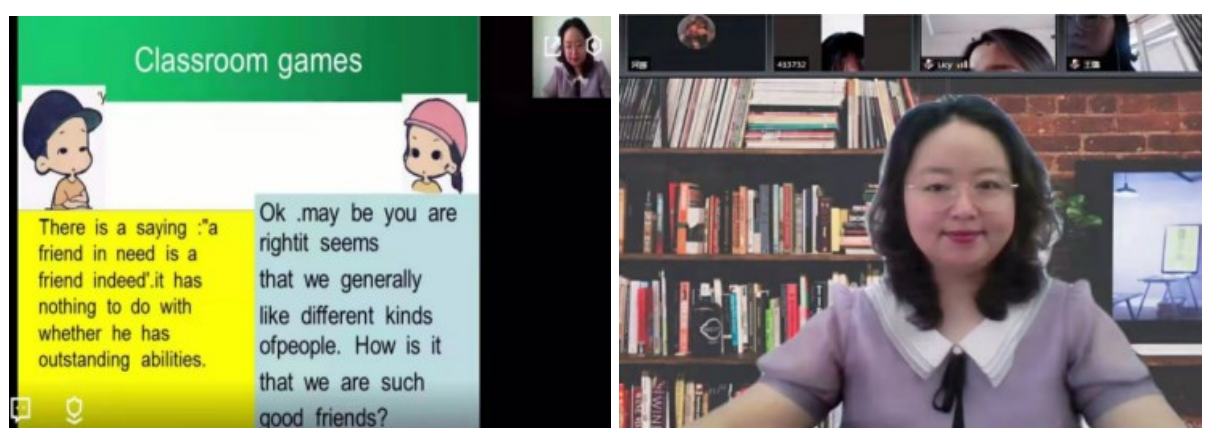

Fig. 6. The demonstration of consolidating scenes in the class of blended collaborative teaching mode 
Step 3: Expanding after class. After class, each student wrote a learning experience and uploaded to QQ group to share with classmates; Meanwhile, the two teachers instructed students who participated in the group report to continue to review, analyse and sort out the literatures, and to finally complete the paper. The flow chart was shown in Fig. 7.

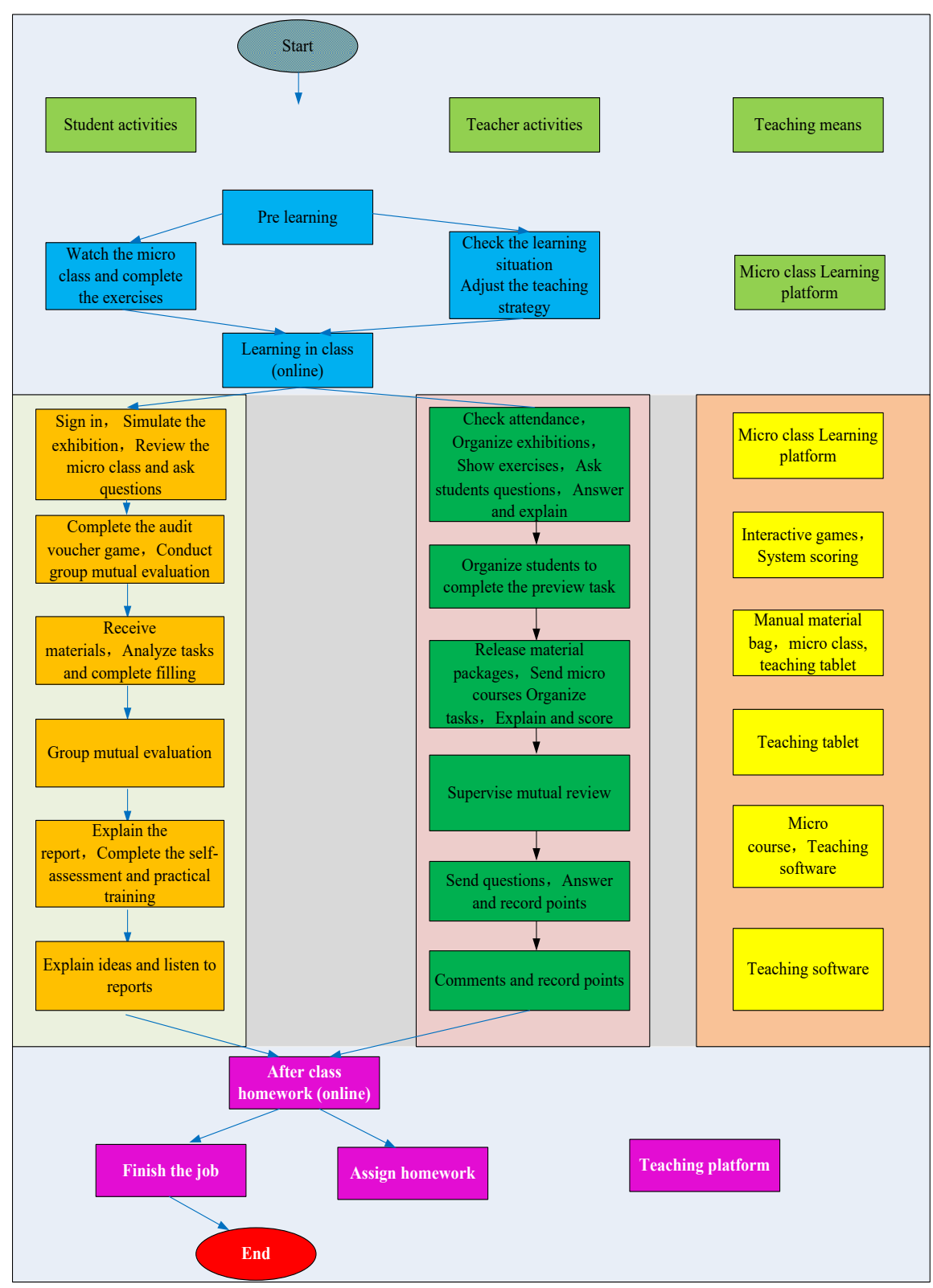

Fig. 7. Flow chart of blended collaborative teaching of college foreign language courses 


\subsection{Teaching effect}

The study was carried out in foreign language courses of freshmen at a college. The teaching effect two classes in same grade were compared. They were randomly divided into one traditional class and one experimental class, with a total of 99 students. Grouped by class, 50 students in class 1 were classified as the experimental group, in which blended collaborative teaching mode was used; 49 students in Class 2 were classified as the control group. There was no significant difference in the scores of the two groups before the experiment, and the two groups had the same teachers and textbooks so that the comparison was available.

A comparison of test scores between the two groups was carried out (see Table 2). As can be seen from Table 2, the usual scores, final scores and total scores of the experimental group were all higher than those of the control group, and the differences had statistical significance $(\mathrm{P}<0.05)$.

Table 2. Comparison of test scores between the experimental group and the control

\begin{tabular}{|l|c|c|c|c|c|}
\hline \multicolumn{1}{|c|}{ Group } & Usual scores & Final scores & t & P & Total scores \\
\hline Experimental group $(\mathrm{n}=50)$ & $26.1 \pm 4.8$ & $63.2 \pm 3.9$ & -2.228 & 0.024 & $89.3 \pm 8.7$ \\
\hline Control group $(\mathrm{n}=49)$ & $22.4 \pm 3.1$ & $58.6 \pm 2.2$ & -2.302 & 0.028 & $81.0 \pm 5.3$ \\
\hline
\end{tabular}

The results have shown that the blended collaborative teaching mode could significantly improve students' performance. Students' listening ability, oral expression ability and writing ability were all better in this mode. Secondly, the self-study ability of students, which were represented by their learning interest, learning motivation, learning enthusiasm and initiative and other aspects, were also improved. By using the blended collaborative teaching mode, students' interest in using mobile phones and other electronic products were satisfied, and knowledge were acquired in the process. This sense of harvest and fulfilment would further stimulate them to make more progress, experience fun in learning and thus stimulate their enthusiasm and proactivity in learning. In the long run, students gradually developed the habit of independent learning. It is important to cultivate students' interest in foreign language learning, and this teaching mode can fully stimulate students' interest in learning and lay a foundation for further learning. At the same time, students' teamwork spirit and innovation ability were also enhanced. The blended collaborative teaching mode gave students more initiative in the teaching process, paid attention to guide students to solve problems of online study through cooperative discussion, and focused on the cooperation among them. Therefore, in this teaching mode and with the knowledge recommendation system, students had better collaboration compared to traditional teaching, which was more beneficial for their understanding of knowledge. Meanwhile, the mode is student-centred, which can give full play to their main body status, guide them to independently solve problems and improve their innovation ability. 


\section{Conclusions}

The paper has sorted the concepts and research status of blended collaborative teaching mode and applied it in the teaching design of foreign language courses. A "Three Classes" consisted of "Communication Classroom", "Famous Teacher Classroom" and "Elite Network Classroom" was established to improve the teaching effect of foreign language. The main research achievements are as follows:

- Blended collaborative teaching mode is beneficial to students' online self-study and offline in-class study. The mode takes offline teaching as the core, fully gives play to the function of preview and after-class supervision, making online teaching serve for offline teaching.

- The "Three Classes" provides techniques for the expansion of college foreign language teaching and innovative application of online learning. The variation of this time and space can directly influence the teaching organization structure and management, improving the reform of teaching method and student's learning pattern and improving the teaching effect.

- The online recommendation algorithm can scientifically collect data and establish a performance evaluation system of foreign language learning supported by big data. The results have shown that the method proposed has some effect in improving the recommendation effect. The mode analyses different preferences of students according to their historical behaviours, carries out information filtering, and finally provides personalized recommendation contents, which is beneficial to improving students' learning interest.

\section{References}

[1] Pozdeeva, S., Obskov, A. Justification of the Main Pedagogical Conditions of Interactive Teaching a Foreign Language in High School. Procedia - Social and Behavioral Sciences, 2015, vol. 206, pp. 166-172. https://doi.org/10.1016/j.sbspro.2015.10.047

[2] Troyan, F.J. Learning to Mean in Spanish Writing: A Case Study of a Genre-Based Pedagogy for Standards-Based Writing Instruction. Foreign Language Annals, 2016, vol. 49(2), pp. 317-335. https://doi.org/10.1111/flan.12192

[3] Fortin, A. Development of Generic Competencies: Impact of a Mixed Teaching Approach on Students' Perceptions. Accounting Education, 2010, vol. 19(1-2), pp. 93-122. https://doi. org/10.1080/09639280902888195

[4] Akcaoglu, M., Lee, E. Increasing Social Presence in Online Learning through Small Group Discussions. International Review of Research in Open and Distance Learning, 2016, vol. 17(3), pp. 1-17. https://doi.org/10.19173/irrodl.v17i3.2293

[5] Lee, K.H., Fu, D., Leong, M., et al. Nonparametric Online Learning Control for Soft Continuum Robot: An Enabling Technique for Effective Endoscopic Navigation. Soft Robotics, 2017, vol. 4(4), pp. 324-337. https://doi.org/10.1089/soro.2016.0065

[6] Hébert, T.P., Corcoran, J.A., Coté, J.M, et al. It's Safe to Be Smart: Strategies for Creating a Supportive Classroom Environment. Gifted Child Today, 2014, vol. 37(2), pp. 95-101. https://doi.org/10.1177/1076217514520966 
Paper-A Blended Collaborative Teaching Mode in Language Learning Based on Recommendation ...

[7] Hwang, G.J., Wu, C.H., Tseng, J., et al. Development of a ubiquitous learning platform based on a real-time help-seeking mechanism. British Journal of Educational Technology, 2011, vol. 42(6), pp. 992-1002. https://doi.org/10.1111/j.1467-8535.2010.01123.x

[8] Auster, C. J. Blended Learning as a Potentially Winning Combination of Face-to-face and Online Learning An Exploratory Study. Teaching Sociology, 2016, vol. 44(1), pp. 39-48. https://doi.org/10.1177/0092055x15619217

[9] Chilingaryan, K.P., Ekaterina, Z. Methodology of Flipped Classroom as a Learning Technology in Foreign Language Teaching. Procedia - Social and Behavioral Sciences, 2017, vol. 237, pp. 1500-1504. https://doi.org/10.1016/j.sbspro.2017.02.236

[10] Mugimu, C.B., Sekiziyivu, S. Authentic Instructional Materials and the Communicative Language Teaching Approach of German as Foreign Language in Uganda. 2016, vol. 15(5), pp. 61-74.

[11] Zeng, H.H., Yang, T.H. Research on the application of Hybrid Teaching Model Based on SPOC + rain classroom -- Taking College English as an example. Software Guide, 2019, vol. 18(10), pp. 50-54,57.

[12] Li, X.P. Assessment for Learning in College English Teaching of Reading and Writing. College English Teaching \& Research, 2016, vol. 28(5), pp. 72-75.

\section{Author}

Ting Wang is a Lecturer in the Zibo Vocational Institute, Zibo, Shandong.

Article submitted 2021-10-03. Resubmitted 2021-11-05. Final acceptance 2021-11-08. Final version published as submitted by the author. 